\section{Outcomes of corneal transplantation: a corneal surgeon vs the general ophthalmologist}

Aims The aim of this study was to examine the outcomes of corneal transplantation in cases performed by a group of general ophthalmologists and those performed by an ophthalmologist with a subspecialist interest in corneal surgery.

Methods A retrospective analysis of the outcomes in corneal transplantation was carried out for a 4-year period in three separate units in South Wales. In addition to patient demographic details, the primary diagnosis, type of keratoplasty performed, and outcome of surgery were noted. The data were analysed statistically by the Mann-Whitney $U$-test (onetailed).

Results Group A $(n=35)$ was defined as those patients whose surgery was performed by a general ophthalmologist. There were seven surgeons in this group with a mean of five procedures each over the study period. Group B $(n=54)$ were all operated on by the same surgeon. The mean age in both groups was similar with group A comprising of $66 \%$ males with $50 \%$ males in group B. The commonest indication for surgery in both groups was endothelial cell failure In group A, graft clarity at 1 year was $83 \%$ for all aetiologies and $73 \%$ at 2 years. In group $B$, the results were 97 and $92 \%$, respectively. In group $\mathrm{A}$, overall $56 \%$ achieved $6 / 18$ or better compared with $68 \%$ in group B. In group A $73 \%$ had an improvement of one or more lines compared with $84 \%$ in group $B(P=0.085)$. Reasons for graft failure in both groups were similar.

Conclusion The success rate of corneal transplantation carried out by general ophthalmologists in this study is reduced when compared with cases performed by a corneal surgeon. The explanation for this is not clear, but is undoubtedly multifactorial. Eye (2003) 17, 727-730. doi:10.1038/

sj.eye. 6700486
DW Teenan', KT Sim² and NR Hawksworth²

Keywords: cornea; penetrating keratoplasty; treatment outcome

\section{Introduction}

Penetrating keratoplasty (PK) is the commonest type of allografting undertaken in Britain, with over 3000 being carried out each year. ${ }^{1}$ The indications for corneal grafting have changed gradually since the technique was first described..$^{2-5}$ Recently, however, the number of corneal donations have fallen from 4419 in 1996 to 3346 in $1998 .^{6}$ Attempts have been made to increase the number of corneal donations, ${ }^{7}$ but shortage of graft material continues to be a problem. Unlike solid organ transplantation, which is carried out by a few specialist centres, any ophthalmic surgeon has historically undertaken PKs. In this era of subspecialisation and shortage of donor tissue, is there a place for the part-time corneal graft surgeon? The aim of this study was to examine the outcomes of corneal transplantation in cases performed by a group of general ophthalmologists and those performed by an ophthalmologist with a subspecialist interest in corneal surgery.

\section{Method}

The records of patients undergoing corneal transplantation over a 4-year period in three separate units in South Wales were reviewed. Details observed were patient's age, sex, primary diagnosis, type of keratoplasty performed, and outcome of surgery in terms of graft survival and visual results. The data obtained was analysed statistically by the Mann-Whitney $U$-test (one tailed) to ascertain if patients operated on by a corneal surgeon had better outcomes.
${ }^{1}$ Tennent Institute of Ophthalmology Gartnavel General Hospital Glasgow, UK

${ }^{2}$ Royal Glamorgan Hospital Llantrisant, UK

Correspondence:

DW Teenan

Tennent Institute of Ophthalmology Gartnavel General Hospital 1053 Great Western Road Glasgow G120YN, UK Tel: + 441412112934 Fax: + 441412112054

E-mail: david@

teenan.freeserve.co.uk

Received: 30 September 2002

Accepted in revised form: 17 December 2002

Poster presentation, Royal College of Ophthalmologists Annual Congress, Manchester 2002 


\section{Results}

Group A $(n=35)$ was defined as those patients whose surgery was performed by a general ophthalmologist. There were seven surgeons in this group with a mean of five procedures each over the study period. Group B $(n=54)$ were all operated on by the same corneal surgeon. The mean age in both groups was similar. Group A comprised of $66 \%$ males and group B 50\% males. The indications for keratoplasty were classified into, dystrophies, regrafts, keratoconus, tectonic/trauma, herpes simplex keratitis, and endothelial cell failure, including Fuchs' endothelial dystrophy as well as aphakic and pseudophakic bullous keratopathy. The commonest indication for surgery in group A was endothelial cell failure (56\%) with $79 \%$ of this group consisting of patients with pseudophakic bullous keratopathy and the remainder having a diagnosis of Fuchs' endothelial cell dystrophy. In group B, the picture was similar with the commonest indication again being endothelial cell failure (42\%); however, in this group the majority of cases were because of Fuchs' endothelial cell dystrophy (61\%) (Figures 1 and 2). PK was performed in all cases in group A, except five (14.3\%), which were combined with cataract extraction. In group B, $61 \%$ were PK, 29\% were combined PK and cataract extraction, and $10 \%$ were deep lamellar keratoplasties. In group A, graft clarity at 1 year was $83 \%$ for all aetiologies and $73 \%$ at 2 years. In group B, the results were 97 and $92 \%$, respectively. As expected, graft clarity varied with the primary diagnosis. In both groups over $80 \%$ of keratoconic patients achieved $6 / 18$ or better with no

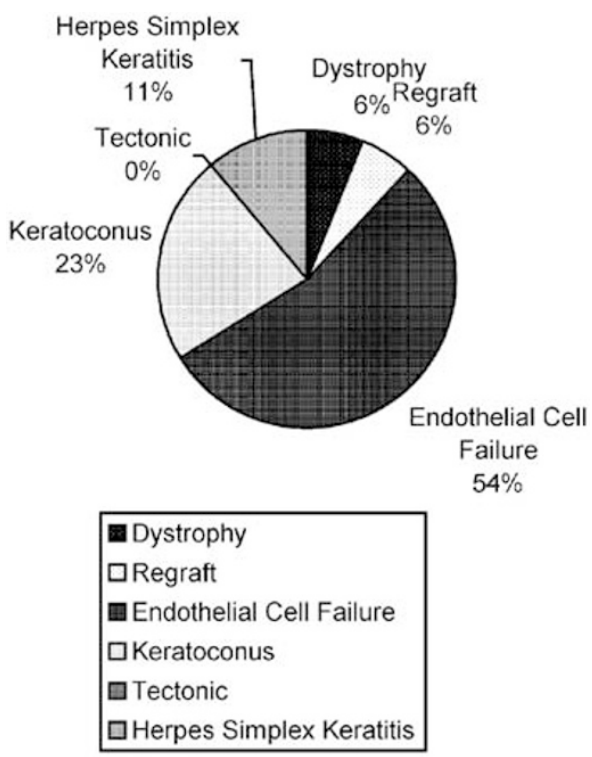

Figure 1 Indications; group A. episodes of graft failure. In group A, overall $56 \%$ achieved $6 / 18$ or better compared with $68 \%$ in group $B$ $(P=0.085)$ (Figures 3 and 4$)$. In terms of change in Snellen's acuity, 73\% in group A had an improvement of one or more lines compared with $84 \%$ in group B $(P=0.067)$ (Figure 5). In group A there were six $(17.1 \%)$ cases of graft failure, while in group B there were four (7.4\%). Reasons for graft failure in both groups were similar and included uncontrolled intraocular pressure, globe rupture, epitheliopathy, and bacterial/viral keratitis. In group A there were six episodes of graft rejection and eight in group B, all resolved with intensive medical treatment and none led to graft failure.

\section{Discussion}

For a corneal graft to be successful, it must not only be a technical success but the patient must also feel a benefit, either visually or in terms of comfort. In both groups of this study an improvement in Snellen's visual acuity was noted; this however fails to take into account the impact on the patient's lifestyle and on his or her ability to function on a daily basis. Previous studies have found that glare in the operated eye can result in loss of visual function, ${ }^{8}$ and needs to be addressed. When undertaking a PK, the surgeon must be confident in their ability to manage the patient satisfactorily postoperatively. This includes correcting refractive errors either surgically or optically in which case a good optometric back-up service is required. Other reasons for poor visual

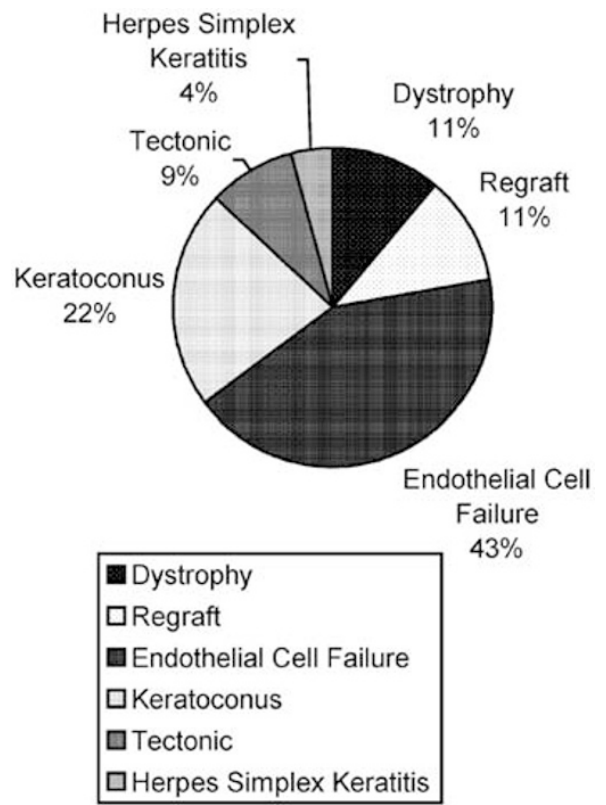

Figure 2 Indications; group B. 


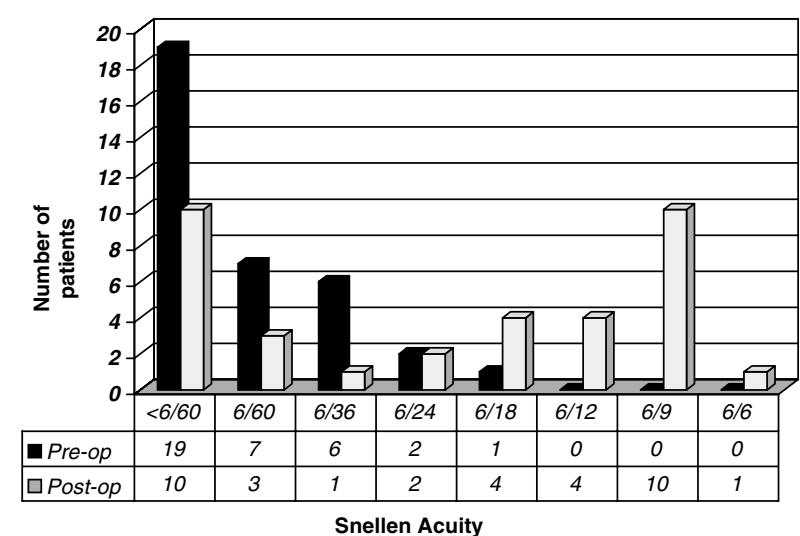

Figure 3 Visual acuity; group A.

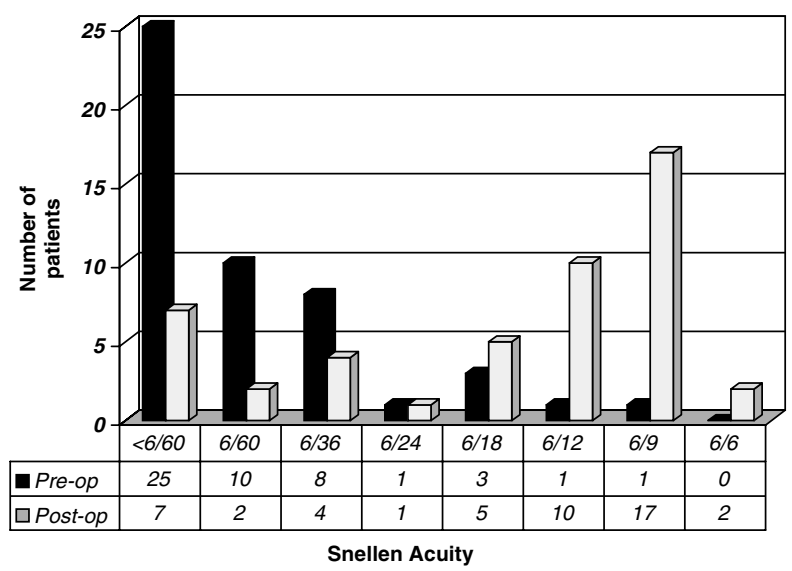

Figure 4 Visual acuity; group B.

rehabilitation include comorbidity, and this must be taken into account and discussed with the patient preoperatively so as not to increase unduly the patient's expectations.

The number of patients in this study is small, but it can be seen that the incidence of graft failure is higher in group A than in group B. In both groups, the figures were comparable to the published series. ${ }^{9,10}$ The reasons why the outcomes of corneal grafts should differ from series to series are complicated and multifactorial. Although surgical technique may be one factor, it is likely that careful patient selection plays a major role in this. With the face of corneal surgery changing and newer techniques such as deep lamellar keratoplasty, which has a steep learning curve, it is likely that corneal grafting, either penetrating or lamellar, will fall exclusively into the domain of the corneal surgeon.

In conclusion, this study suggests that the success rate of corneal transplantation in terms of graft survival and

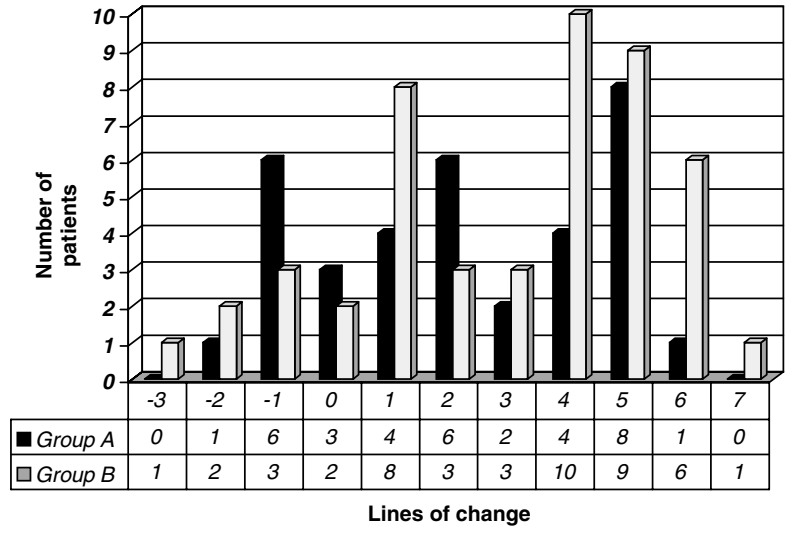

Figure 5 Change in acuity.

final visual acuity is higher in those cases performed by a corneal surgeon than those performed by a general ophthalmologist. Increased experience with corneal surgery improves the outcome of corneal transplantation. The reasons are not clear, but may include many factors such as case selection. Increased surgical numbers also result in a higher number of postoperative patients, which in turn may allow earlier recognition of complications, with prompt and aggressive management regimens implemented by members of the corneal team.

\section{Acknowledgements}

We thank the surgeons in the Royal Gwent Hospital, Newport and Singleton Hospital, Swansea for their permission to involve their patients in this study.

\section{References}

1 Tullo AB, Dyer PA. Corneal transplantation in Britain. BMJ 1995; 310(6991): 1347-1348.

2 Smith RE, McDonald HR, Nesburn AB, Minckler DS. Penetrating keratoplasty: changing indications, 1947-1978. Arch Ophthalmol 1980; 98(7): 1226-1229.

3 Brady SE, Rapuano CJ, Arentsen JJ, Cohen EJ, Laibson PR. Clinical indications for and procedures associated with penetrating keratoplasty, 1983-1988. Am J Ophthalmol 1989; 108(2): 118-122.

4 Arentsen JJ, Morgan B, Green WR. Changing indications for keratoplasty. Am J Ophthalmol 1976; 81(3): 313-318.

5 Ramsay AS, Lee WR, Mohammed A. Changing indications for penetrating keratoplasty in the west of Scotland from 1970 to 1995. Eye 1997; 11(Part 3): 357-360.

6 United Kingdom Transplant Support Service Authority. Statistics Prepared by UK Transplant Support Service Authority from the National Transplant Database Maintained on Behalf of the UK Transplant Community. UKTSSA:Bristol, 1999. 
7 Long J, Walsh D, Ritchie DA, Russell F. Corneal donation in the accident and emergency department: observational study. BMJ 2000; 321(7271): 1263-1264.

8 Carney LG, Jacobs RJ. Problems remaining after successful keratoplasty for keratoconus. Clin Exp Optom 1989; 72 22-25.
9 Vail A, Gore SM, Bradley BA, Easty DL, Rogers CA, Atmitage WJ. Conclusions of the corneal transplant follow up study. Br J Ophthalmol 1997; 81: 631-636.

10 Williams KA, Roder D, Esterman A, Muehlberg SM, Coster DJ. Factors predictive of corneal graft survival: report from the Australian Corneal Graft Registry. Ophthalmology 1992; 99: 403-414. 